\title{
Reply to Proffitt, Stefanucci, Banton, and Epstein
}

\author{
Jeffrey J. Hutchison ${ }^{1}$ and Jack M. Loomis ${ }^{2}$ \\ ${ }^{1}$ Brown University \\ ${ }^{2}$ University of California
}

\begin{abstract}
In this reply, we acknowledge that methodological differences between the experiment of Proffitt et al. (2003) and ours might explain our failure to replicate their finding. However, we maintain that our results obtained with three different response measures point to a lack of robustness. In this reply, we acknowledge that methodological differences between the experiment of Proffitt et al. (2003) and ours might explain our failure to replicate their finding. However, we maintain that our results obtained with three different response measures point to a lack of robustness of their finding. In response to their criticism of using blind walking to measure perceived distance, we argue on theoretical grounds that blind walking, while involving post-perceptual processes, can nevertheless provide a measure of perceived distance, and then cite some of the evidence indicating that it does indeed provide such a measure.
\end{abstract}

Keywords: perceived distance, blind walking, visually directed action

En esta réplica, los autores reconocen que las diferencias metodológicas respecto al experimento de Proffit et al. (2003) podrían explicar el fallo en la replicación. Sin embargo, se indica que la obtención de resultados negativos en tres medidas diferentes parece implicar una escasa fortaleza en el efecto. Por otra parte, y en respuesta a las críticas sobre el uso de caminar a ciegas para medir la distancia percibida, se argumenta teóricamente que esta conducta puede proporcionar una medida adecuada de la distancia percibida, aunque implique procesos posteriores a la percepción. También se cita alguna evidencia en apoyo de esta conclusión.

Palabras clave: distancia percibida, caminar a ciegas, acción dirigida visualmente.

Address correspondence to Jeffrey J. Hutchison, Department of Cognitive and Linguistic Sciences, Brown University, Providence, RI 02192 (USA). E-mail: Jeffrey_Hutchison@brown.edu 
In their reply to our article (Hutchison \& Loomis, this issue), Proffitt, Stefanucci, Banton, and Epstein (this issue) offer several criticisms concerning methodological differences and several concerning theoretical issues.

\section{Methodological Differences}

We acknowledge methodological differences between the two studies. Proffitt et al. (this issue) have pointed to these differences as possible reasons for our failure to replicate the results of their Experiment 1. Certainly, our experiments did not precisely duplicate the procedures of their experiment, and had we followed their procedures more faithfully, we might have obtained their results. Still, as stated in our article, our experiments cast doubt on the robustness of the claimed finding of their Experiment 1that wearing a heavy backpack causes visually perceived distance to increase.

Proffitt et al. (this issue) offer three methodological criticisms of our work: (a) that the use of a within-participants design in our second experiment was inappropriate, (b) that our use of two other responses in Experiment 1 likely reduced the effect of the backpack manipulation on verbal reports, and (c) that we did not give participants practice with verbal reports and obtained too few verbal reports in our Experiment 1 , thus obtaining noisier verbal report data with a consequent lower statistical power. We respond to these criticisms in order.

\section{Criticism 1}

Because our Experiment 1 had failed to show a statistically significant effect of the backpack with our between-participants design, we conducted Experiment 2 using a within-participants design in the hope that increasing statistical power would reveal such an effect. We agree with Proffitt et al. (in press) that a within-participants design is likely to cause participants to realize the intent of the backpack manipulation. However, even if they did, it is not obvious how such a realization would eliminate the putative perceptual effect of the backpack hypothesized by the authors.

\section{Criticism 2}

In Experiment 1 of Proffitt, Stefanucci, Banton, \& Epstein (2003), participants were only asked to make distance judgments. In our Experiment 1, participants made verbal distance judgments, verbal size judgments, and walked indirectly to the targets, and in Experiment 2, they made both verbal size and distance judgments. Proffitt et al. (this issue) argue, based on their more recent theoretical interpretation (Witt, Proffitt, \& Epstein, 2004), that the influence of effort on perception is dependent upon the next action the participant expects to perform. Thus, they state that "When H\&L's participants judged target distances, it was with the anticipation that they would next perform actions other than walking the extent. H\&L's participants did not anticipate that they would ever walk directly to the target, and for this reason, they may not have been influenced by the effort required to walk this extent." We find it strange that Proffitt et al. make this argument, for in Experiment 1 of Proffitt et al. (2003), participants were only asked to make verbal distance estimates, according to the procedure reported in their article. If their participants never actually did walk to targets, then they presumably did not anticipate doing so. Without the expectation of walking, why would there have been any influence of effort on judgments of perceived distance, as reported in their results?

\section{Criticism 3}

We agree that our failure to obtain a statistically significant effect of the backpack manipulation on verbal estimates of distance might be the result of less reliable verbal estimates and that had we given participants practice with verbal reports and had we obtained multiple judgments at each distance, a statistically significant effect might have resulted. However, Proffitt et al. (2003) claim that backpack manipulation affects perceived distance, not merely verbal estimates of perceived distance. In their reply, they state that both the distance and size judgments in Experiment 1 showed trends in the expected direction. Thus, it seems, they agree that size judgments, along with distance judgments, ought to be affected by the backpack manipulation. In our article, we argued for the use of indirect blind walking as still another measure of perceived distance. In Experiment 1 we demonstrated that the field of view manipulation produced reliable and consistent influences on the three measures utilized: verbal distance, verbal size, and blind walking. The absence of statistically significant effects of the backpack manipulation for any of the three measures of perceived distance casts doubt on the robustness of their claimed effect of wearing a backpack

\section{Theoretical Issues}

Proffitt et al. (this issue) find fault with our intended use of indirect blind walking ("triangulated walking" in their terminology) as a means of obtaining a "purer" measure of perceived distance, "purer" in the sense of being less subject to cognitive influences than are verbal reports. Although we do not believe that any measure of perceived distance is "pure" in an absolute sense, we do believe that indirect blind walking is less subject to cognitive influences than verbal report. Whether it is or is not ultimately is a matter that needs to be settled by empirical and theoretical research. 
In discussing indirect blind walking, Proffitt et al. (this issue) state the following. "The measure is performed without vision; by definition, it is post-perceptual. Only through convoluted argument could it be asserted that a measure obtained without vision is a 'purer' measure of visual perception than one in which vision is unfettered." Although indirect blind walking clearly depends on post-perceptual processes, it does not follow that such a response cannot provide a measure of perceived distance purer than one based on a response when vision is present. A valid measuring instrument is one for which the variations in the indicated values are correlated with variations in the variable being measured and for which a calibration between the two has been established; the indirectness of the mediation between the variable being measured and the indicator is not an issue. In the case of indirect blind walking (as well as all other forms of visually directed action), the measured response is a valid measure of perceived distance provided that post-perceptual processes introduce no systematic biases or, if they do, that the biases can be corrected for by way of calibration. Aside from the random variability associated with each subsequent process (measurement noise), indirect blind walking can in principle provide an unbiased (i.e., relatively pure measure) of perceived distance.

Proffitt et al. (this issue) then go on to question whether indirect blind walking does in fact reflect variations in perceived distance. There is a great deal of evidence showing that visually-directed action, of which indirect blind walking is a special case, does indeed reflect perceived distance. This evidence is reported in a number of articles cited by Hutchison and Loomis (this issue) and is also reviewed by Loomis and Philbeck. The strongest evidence comes from studies showing that the response measures provided by visually directed action covary tightly with other measures of perception, such as verbal reports of perceived distance (Philbeck \& Loomis, 1997) and judgments of visually perceived shape (e.g., Ooi, $\mathrm{Wu}, \& \mathrm{He}$, in press; Wu, Ooi, $\& \mathrm{He}, 2004)$. As for their argument that indirect blind walking might be based directly on angular elevation information rather than on perceived location, of which perceived distance is one component, research using related tasks of visually directed action show this not to be case. In two studies involving targets on the ground viewed with impoverished distance cues, Ooi, Wu, and $\mathrm{He}$ (2001, in press) have shown that participants indicate perceived locations that are consistent with the angular elevations of the targets but are closer than the targets and thus above the ground. Were the responses of the participants determined solely by angular elevation information, they ought to have indicated target locations on the ground plane. Now when visual cues are abundant and indicated distance ends up being generally accurate, it is natural to presume that people continue to respond to the perceived locations (including their constituent perceived distances) rather than to angular elevation per se (e.g., Philbeck \& Loomis, 1997).

\section{References}

Hutchison, J.J., \& Loomis, J.M. (this issue). Does energy expenditure affect the perception of egocentric distance? A failure to replicate Experiment 1 of Proffitt, Stefanucci, Banton, and Epstein (2003).

Loomis, J.M., \& Philbeck, J.W. Measuring perceived egocentric distance with spatial updating and action. Manuscript submitted for publication.

Ooi, T.L., Wu, B., \& He, Z.J. (2001). Distance determined by the angular declination below the horizon. Nature, 414, 197-200.

Ooi, T.L., Wu, B., \& He, Z.J., (in press). Perceptual space in the dark affected by the intrinsic bias of the visual system. Perception.

Philbeck, J.W., \& Loomis, J.M. (1997). Comparison of two indicators of perceived egocentric distance under full-cue and reduced-cue conditions. Journal of Experimental Psychology: Human Perception and Performance, 23, 72-85.

Proffitt, D.R., Stefanucci, J., Banton, T., \& Epstein, W. (2003). The role of effort in distance perception. Psychological Science, 14, 106-113.

Proffitt, D.R., Stefanucci, J., Banton, T., \& Epstein, W. (this issue). Reply to Hutchison and Loomis.

Witt, J.K., Proffitt, D.R., \& Epstein, W. (2004). Perceiving distance: A role of effort and intent. Perception, 33, 577-590.

Wu, B., Ooi, T. L., He, Z.J. (2004) Perceiving distance accurately by a directional process of integrating ground information. Nature, 428, 73-77.

Received April 10, 2006

Review received April 24, 2006 Accepted April 26, 2006 